\title{
Mapping evidence of the concomitant management of schistosomiasis by traditional health practitioners and health care professionals in communities with high prevalent infections: a systematic scoping review protocol
}

\author{
Gloire-Aimé Aganze Mushebenge ${ }^{1 *}\left(\mathbb{D}\right.$, Tivani Mashamba-Thompson² and Manimbulu Nlooto ${ }^{1}$
}

\begin{abstract}
Background: Schistosomiasis is one of the most prevalent parasitic diseases in low- and middle-income countries (LMICs), being regarded as a neglected tropical disease in sub-Saharan Africa. Praziquantel is the conventional treatment recommended for schistosomiasis in mainstream healthcare systems. In many poor settings, while many people reportedly use both traditional medicine and public sector mainstream healthcare systems, little is known if those infected with schistosomiasis use both African traditional and prescribed antischistosomal medicines. This review aims to map evidence of the concomitant management of schistosomiasis by traditional health practitioners (THPs) and health care professionals (HCPs) in communities with a high prevalence schistosomiasis infection in LMICS.

Methods/design: Guided by Arksey and O'Malley scoping review framework and Preferred Reporting Items for Systematic Reviews and Meta-Analyses (PRISMA), we will map the evidence from relevant studies dating from 2007 to 2019 published in LMICs. An electronic keyword search of the following databases will be conducted: PubMed, Cochrane Library, the Cumulative Index to Nursing and Allied Health Literature (CINAHL), and MEDLINE via EBSCOhost, Google Scholar, and WILEY online Library. Peer-reviewed articles, gray literature sources, and reference lists will be included to identify eligible studies. Following title screening, two reviewers will independently screen the abstracts and full texts. Any study that focuses on managing schistosomiasis will be included. The data will be analyzed using thematic analysis with the help of NVIVO software version 12, with the Mixed Method Appraisal Tool (MMAT) being used to assess the quality of the included studies.
\end{abstract}

Discussion: This review will map the evidence in the literature of the concomitant management of schistosomiasis by THPs and HCPs in communities with a high prevalent infection in LMICs. The review findings will be important for policy makers across the healthcare continuum and be used to inform stakeholders' consensus process to explore the development of a generic set of patient-centered quality indicators that are applicable to multiple care settings. It will also identify research gaps in schistosomiasis management in LMICs and provide direction for future research. The results will be disseminated through a peer-reviewed publication and presented in relevant conferences.

(Continued on next page)

\footnotetext{
* Correspondence: aganzedar@Gmail.com

${ }^{1}$ Discipline of Pharmaceutical Sciences, School of Health Sciences, University

of KwaZulu-Natal, 6th Floor, E Block Building, Westville Campus, P B X54001,

Durban 4000, South Africa

Full list of author information is available at the end of the article
}

(c) The Author(s). 2019 Open Access This article is distributed under the terms of the Creative Commons Attribution 4.0 International License (http://creativecommons.org/licenses/by/4.0/), which permits unrestricted use, distribution, and reproduction in any medium, provided you give appropriate credit to the original author(s) and the source, provide a link to the Creative Commons license, and indicate if changes were made. The Creative Commons Public Domain Dedication waiver (http://creativecommons.org/publicdomain/zero/1.0/) applies to the data made available in this article, unless otherwise stated. 
(Continued from previous page)

Systematic review registration: PROSPERO CRD42017078198

Keywords: Schistosomiasis, Neglected tropical diseases, Collaboration, Investigation, Traditional health practitioners, Health care professionals, Access, Low- and middle-income countries

\section{Background}

Infectious diseases are both a major public health concern and a socioeconomic problem in tropical regions within most low- and middle-income countries (LMICs), where neglected tropical diseases (NTDs), such as schistosomiasis, are cause for concern [1]. These NTDs often occur in people who are also infected with human immunodeficiency virus (HIV), malaria, or tuberculosis, making the problem even more serious, as co-infections are common [2]. Globally, more than 250 million people are infected with schistosomiasis, with approximately 700 million at risk of infection [3]. Schistosomiasis is a parasitic disease caused by schistosomes, worms that are found in tropical and subtropical fresh waters [4]. An estimated 206.4 million people needed preventive treatment for schistosomiasis in Africa in 2016, of whom approximately 89 million (43\%) were reportedly treated [5]. More than five million people in South Africa, mainly in rural areas, required treatment in 2014 for urogenital schistosomiasis [6].

Praziquantel, the recommended treatment against all forms of schistosomiasis [7], is inexpensive and regarded as effective and safe, although re-infection may occur after treatment. The risk of developing severe disease is reduced when treatment is initiated and repeated in childhood [8]. Many countries, such as Mozambique, Zambia, Nigeria, and Uganda, have implemented mass treatment campaigns since the 1980 s with generic medicines, including praziquantel, with some having attained countrywide coverage the last few years [9-11]. The cost of praziquantel in South Africa is 50 times higher than the World Health Organization (WHO) standard treatment that is in use in the rest of Africa, making it costly to provide mass treatment, which cannot be implemented [12]. None of the companies producing generic praziquantel in other countries have the right to sell them in South Africa, due to the time-consuming, expensive, "scientifically unnecessary," and elaborate registration process [13]. However, the cost of praziquantel in South Africa, despite having been reduced, remains prohibitive for many control programs in schistosomiasis endemic areas [14].

Alternatively, traditional medicine has demonstrated its contribution to managing schistosomiasis [15]. In an ethnopharmacological survey conducted in Niger and Mali, 55 plant species were reported to be used for treating schistosomiasis either alone or in combination, of which Zea mays with Glossonema boveanum were specific for intestinal schistosomiasis, while Cissus quadrangularis and Stylosanthes erecta were reported for the first time in Mali to be used against urogenital schistosomiasis [16]. A range of medicinal plants with anti-schistosomiasis properties have been widely used by traditional healers of different tribes in South Africa, although their effectiveness has not been scientifically evaluated [14]. A study conducted on mice in Zimbabwe showed no significant difference between an herbal preparation (Schitozim) and praziquantel in managing schistosomiasis. However, the authors warranted further investigation to determine the toxic levels and effective doses of Schitozim in humans [17].

Due to the unavailability of conventional therapy, or the expensive cost of praziquantel and other antischistosomal medicines, people in rural areas may not have access to modern treatment for schistosomiasis, which results in them using traditional medicine [18, 19]. Collaboration between the two medical traditions can provide appropriate care for diseases management, for example, through mutual referral [20].

This review aims to map the evidence of the concomitant management of schistosomiasis by traditional health practitioners and health care professionals in communities with a high prevalence of schistosomiasis infection in LMICs. Thus, the purpose of this review is to provide evidence to enable the implementation of policies and guidelines to manage schistosomiasis with traditional medicine contributing to primary healthcare.

\section{Methods/design \\ Scoping review framework}

This review will be based on the framework originally proposed by Arksey and O'Malley [21] and further improved by Levac et al. [22], which are presented in Table 1 [21-23]. There are six steps involved in the framework, although the last step about consulting experts/stakeholders will not be conducted for this review due to funding constraints. Consulting additional sources of information, perspectives, meaning, and applicability will be covered with gray literature. This review follows the six steps outlined by the Arksey and O'Malley framework, but will incorporate enhancement suggested by the later authors.

\section{Identify the research questions}

The following research questions are formulated to guide the review in meeting its aims and objectives. The general research question is: "What is the evidence 
Table 1 Scoping review framework for this review [21-23]

\begin{tabular}{ll}
\hline Arksey And O'Malley framework & $\begin{array}{l}\text { Enhancements proposed by } \\
\text { Levac, Colquhoun, and O'Brien }\end{array}$ \\
\hline 1. Identify the research question & $\begin{array}{l}\text { Clarify and link the purpose and } \\
\text { research question }\end{array}$ \\
2. Identify relevant studies & $\begin{array}{l}\text { Balance the feasibility with } \\
\text { breadth and comprehensiveness } \\
\text { of the scoping process }\end{array}$ \\
3. Select the study & $\begin{array}{l}\text { Use an iterative team approach } \\
\text { to select studies and extract data }\end{array}$ \\
4. Chart the data & $\begin{array}{l}\text { Incorporate a numerical } \\
\text { summary and qualitative } \\
\text { thematic analysis }\end{array}$ \\
5. Collate, summarize, and report & $\begin{array}{l}\text { Identify the implications of the } \\
\text { study findings for policy, practice, } \\
\text { or research }\end{array}$ \\
6. Consult experts/stakeholders & $\begin{array}{l}\text { Provide opportunities for } \\
\text { consumer and stakeholder } \\
\text { involvement to suggest } \\
\text { additional references and provide } \\
\text { insights beyond those in the } \\
\text { literature }\end{array}$ \\
\hline
\end{tabular}

about the concomitant management of schistosomiasis by THPs and HCPs in communities with a high prevalence schistosomiasis infection?" The specific research questions are as follows:

1. What is the evidence of the healthcare seeking behavior among individuals in communities with high prevalent infections of schistosomiasis?

2. What is the evidence of the use of traditional, complementary, and alternative medicine for managing schistosomiasis?

3. Is there a bidirectional referral of patients between THPs and HCPs for managing schistosomiasis?

Eligibility of research questions The Population, Intervention, Comparison and Outcomes (PICO) for the research questions has been used to break down the clinical questions into searchable keywords (See Table 2) [24].

Table 2 PICO framework

\begin{tabular}{ll}
\hline Framework & Evidence-based practice \\
\hline P: Population & THPs and HCPS, aged 18 years old and above. \\
I: Intervention & $\begin{array}{l}\text { Traditional remedies for schistosomiasis } \\
\text { management, praziquantel, and LMICs. }\end{array}$ \\
C: Comparison & $\begin{array}{l}\text { Schistosomiasis management by THPs and } \\
\text { HCPs. }\end{array}$ \\
O: Outcomes & $\begin{array}{l}\text { Access to treatment and improvement of the } \\
\text { management of schistosomiasis in communities } \\
\end{array}$ \\
& with high prevalent infection. \\
\hline
\end{tabular}

\section{Identify relevant studies}

Relevant literature will be searched from the following databases: PubMed, EBSCOhost (the Cumulative Index to Nursing and Allied Health Literature (CINAHL), MEDLINE, Google Scholar, Cochrane Library, WILEY online Library, and grey literature. Reference lists of included studies will also be searched. The keywords search will include the following: schistosomiasis; neglected tropical diseases; collaboration; investigation, traditional health practitioners; health care professionals; access; low- and middle-income countries, schistosomiasis, or collaboration or traditional medicine or neglected tropical diseases (NTDs) or natural products or leads. The Boolean search terms (AND and OR) and MeSH terms ("therapy", "therapeutics", "schistosomiasis", "health personnel”, "residence characteristics", "infection", ...) will be included in the search. Gray literature will be identified through website source links in references. Peer review studies and gray literature reporting on the evidence of managing schistosomiasis by THPs and HCPs in LMICs published between 2007 and 2019 will be included. Authors of primary studies or reviews will be contacted for further information or to access missing studies where relevant. If the authors do not respond, then their publications will be excluded.

\section{Select the study}

Inclusion criteria The following criteria provide a guide to clearly understand what is proposed by the reviewers and, more importantly, a guide for the reviewers themselves upon which to base decisions about the sources to be included in this review [25]. As explained above, regarding the review types, there must be clear congruency between the title, objectives, question/s, and inclusion criteria of a scoping review. They are as follows:

1. Evidence of the population of interest in this review (THPs and HCPs)

2. Evidence of the intervention (schistosomiasis treatment and co-morbidities)

3. Evidence of the comparison of treatment by THPs and HCPs

4. Evidence on the outcomes of managing schistosomiasis

5. Articles published in English and French will be included.

\section{Exclusion criteria}

1. Articles published before 2007.

2. Articles not addressing the treatment of schistosomiasis and comorbidities.

3. Articles not addressing integration and collaboration between traditional medicine and conventional medicine.

4. Studies that are not reporting evidence from LMICs 
Search strategy The search strategy for this review aims to be comprehensive to identify both published and unpublished (grey literature) primary studies and reviews $[25,26]$. A pilot search was conducted with the database results provided in Additional file 1. A three-step search strategy will be utilized. The first step is an initial limited search of the electronic databases. This initial search will be monitored, exported on EndNote X9 reference manager for abstract and full article screening. The duplicated article will be deleted. A second search using all identified keywords and index terms will then be undertaken across all included databases. Thirdly, the reference list of all identified reports and articles will be searched for additional studies [25]. For abstract and full article screening, the EndNote library will be shared with a second reviewer. Any discrepancies in the results of the abstract screening will be resolved through a discussion until consensus is reached. A third screener will help resolving discrepancies in full article screening results [26].

Publications duplicated in the research results will be treated as a single study for the review. To maintain transparency in the review selection process, a PRISMA Flow Diagram will be followed in each stage of the selection process. In addition, a list of the studies excluded during the full-text review will be documented as an Additional file 2, with brief reasons for their exclusion [26]. A PRISMA Flow Diagram will be used to report the screening results (see Fig. 1). EndNote will help to manage the search results including downloading all results, removing duplicate records, and screening for potentially relevant studies.

Quality appraisal For the quality appraisal of the included studies, we will use a Mixed Methods Appraisal Tool (MMAT), version 2018 [27]. The MMAT will allow us to assess the appropriateness and quality of the research. Studies can be scored following specific criterion using a certain score to describe them from $50 \%$ and above.

\section{Chart the data}

We will conduct data extraction to enable a logical and descriptive summary of the search results (Additional file 1) of our systematic scoping review [25, 26]. A table of characteristics for included studies will be developed at this stage to record the key information of the source, such as author, reference, and results or findings, relevant to the review question/s (Additional file 3). This may be further refined at the review stage and the sample extraction form updated accordingly. From the key

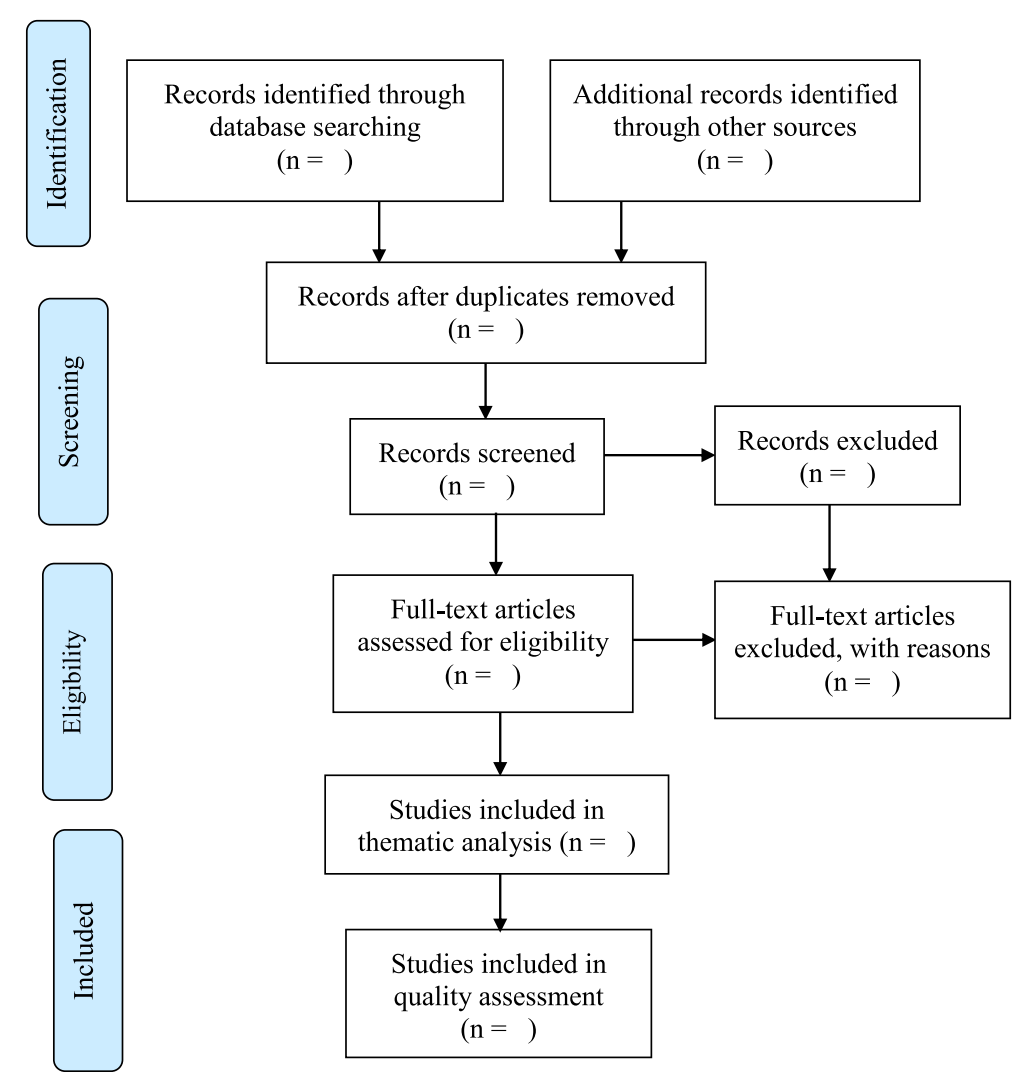

Fig. 1 The PRISMA flow diagram for the scoping review screening process [25] 
information chart, data in the selected articles will be in data extraction form and synthesized into different themes for interpretation to identify key findings.

\section{Collate, summarize, and report the results}

The results will be presented in a data extraction form or table and will be further refined towards the end of the review when the authors will have the greatest awareness of the contents of their included studies to manage schistosomiasis. The results will be mapped in existing thematic framework, which will consist of the included papers in a diagrammatic or tabular form, and/ or in a descriptive format that aligns with the objective/s and scope of the review related to outcomes. The PICO elements for inclusion criteria will be useful to guide how the data will be mapped most appropriately.

A narrative summary will accompany the tabulated and/or charted results and should describe how they relate to the review objective and question/s according to the management of schistosomiasis and its co-morbidities by THPs and HCPs. The synthesis of important findings across the included studies will be classified by identifying prominent themes under main conceptual categories, such as: "intervention type", "review population" (and sample size, if it is the case), "duration of intervention", "aims", "methodology adopted", "key findings" (evidence established), and "gaps in the research". For each category reported, a clear explanation will be provided.

Synthesis Throughout this research, we will examine the above-mentioned themes and critically identify their link to the research question. Reviewers will analyze the significance of the findings according to the aim of this research and their implications for future studies, practice, and policy.

\section{Discussion}

This review is part of larger studies evaluating the management of schistosomiasis by THPs and HCPs in South Africa. There is little evidence to support the current South African policy to manage schistosomiasis. This systematic scoping review aims to build on the work of the existing Cochrane study [20] by further describing the participant inclusion criteria and utilizing a wider range of evidence on this topic. A key strength is that it can provide a rigorous and transparent method for mapping areas of research according to the treatment of schistosomiasis with comorbidities. We wish to be able to illustrate the field of interest, that being the management of schistosomiasis, in terms of the volume, nature, and characteristics of the primary research.

Articles not addressing integration and collaboration between traditional and modern medicine will not be part of this research, as it intends finding a way to manage schistosomiasis via bidirectional referral of patients between THPs and HCPs. Due to the prevalence of schistosomiasis, a collaboration of THPs and HCPs could help to manage the infection, as traditional medicine is available to most people in LMICs, with not less than $80 \%$ of people worldwide depending on it [28].

It is anticipated that this review will identify gaps in the current literature on this topic and provide direction for future research in this area of this review. The summary and dissemination of these research findings may be of interest for policy makers and stakeholders (practitioners and consumers) who are involved in the NTDs management, especially those involved in schistosomiasis management using either the mainstream healthcare systems or African traditional medicine.

\section{Additional files}

Additional file 1: Results of pilot database search. (DOCX 14 kb)

Additional file 2: PRISMA-P (Preferred Reporting Items for Systematic review and Meta-Analysis Protocols) 2015 checklist: recommended items to address in a systematic review protocol. (DOCX $22 \mathrm{~kb}$ )

Additional file 3: Sample extraction form. (DOCX $15 \mathrm{~kb}$ )

\section{Abbreviations}

HCPs: Health care professionals; HIV/AIDS: Human Immunodeficiency Virus/ Acquis immunodeficiency deficiency Syndrome; LMICs: Low- and middleincome countries; MMAT: Mixed Methods Appraisal Tool; NTDs: Neglected tropical diseases; PICO: Population Intervention Comparison Outcomes; THPs: Traditional healthcare practitioners; TM: Traditional medicine

\section{Acknowledgements}

We wish to thank the following: Carrin Martin for her editing services, Sule Ajibola Saka, and Mukanda Gedeon Kadima, Discipline of Pharmaceutical Sciences, University of KwaZulu-Natal, for accepting to read the initial draft of the manuscript and their comments. Authors thank the University of KwaZulu-Natal Systematic Review Services for methodological support.

\section{Authors' contributions}

This review protocol was drafted by AM. MN and TM revised the draft for its intellectual content and approved the final version of the manuscript for submission to the journal. AM and MN addressed peer reviewers' comments. All authors read and approved the final version of the revised manuscript.

\section{Authors' information}

GAAM is a PhD student in the Discipline of Pharmaceutical Sciences, School of Health Sciences, University of KwaZulu-Natal, 6th Floor, E Block Building, Westville Campus, P B X54001, Durban 4000, South Africa Contacts: aganzedar@Gmail.com, +27 6031197 54, ORCID ID: 0000-0001-8745-8097

\section{Funding}

This review has received no funding.

\section{Availability of data and materials}

All data generated or analyzed during this review will be included in the published scoping review

Ethics approval and consent to participate Not applicable

Consent for publication Not applicable 


\section{Competing interests}

The authors declare that they have no competing interests.

\section{Author details}

'Discipline of Pharmaceutical Sciences, School of Health Sciences, University of KwaZulu-Natal, 6th Floor, E Block Building, Westville Campus, P B X54001, Durban 4000, South Africa. ${ }^{2}$ Discipline of Public Health Medicine, School of Nursing and Public Health, University of KwaZulu-Natal, 2nd Floor, George Campbell Building, Science Drive, Howard College Campus, Durban 4001, South Africa.

Received: 1 November 2017 Accepted: 2 July 2019

Published online: 18 July 2019

\section{References}

1. Molyneux DH, Hotez PJ, Fenwick A. "Rapid-impact interventions": how a policy of integrated control for Africa's neglected tropical diseases could benefit the poor. PLoS Med. 2005;2(11):336. https://doi.org/10.1371/journal. pmed.0020336.

2. Boraschi D, Alemayehu MA, Aseffa A, Chiodi F, Chisi J, Del Prete G, Doherty TM, Elhassan I, Engers H, Gyan B. Immunity against HIV/AIDS, malaria, and tuberculosis during co-infections with neglected infectious diseases: recommendations for the European Union research priorities. PLoS Negl Trop Dis. 2008;2(6):255. https://doi.org/10.1371/journal.pntd.0000255.

3. Youssef A, Uga S: Review of parasitic zoonoses in egypt. Trop Med Health 42(1): p. 3-14. available at https://doi.org/10.2149/tmh.2013-23. Accessed 8 Mar 2019

4. Chitsulo L, Engels D, Montresor A, Savioli L. The global status of schistosomiasis and its control. Acta Trop. 2000;77(1):41-51.

5. WHO (World Health Organization): Schistosomiasis, Fact Sheet No 115. Available at https://www.infontd.org/resource/schistosomiasis-fact-sheetn-115. Accessed 11 July 2018.

6. Hotez PJ, Fujiwara RT. Brazil's neglected tropical diseases: an overview and a report card. Microbes Infect. 2014;16(8):601-6.

7. Doenhoff MJ, Pica-Mattoccia L. Praziquantel for the treatment of schistosomiasis: its use for control in areas with endemic disease and prospects for drug resistance. Expert Rev Anti Infect Ther. 2006;4(2):199-210. https://doi.org/10.1586/14787210.4.2.199.

8. Lo NC, Addiss DG, Hotez PJ, King CH, Stothard JR, Evans DS, Colley DG, Lin W, Coulibaly JT, Bustinduy AL. A call to strengthen the global strategy against schistosomiasis and soil-transmitted helminthiasis: the time is now. Lancet Infect Dis. 2017;17(2):64-9.

9. Dorkenoo A, Bronzan R, Ayena K, Anthony G, Agbo Y, Sognikin K, Dogbe K, Amza A, Sodahlon Y, Mathieu E. Nationwide integrated mapping of three neglected tropical diseases in Togo: countrywide implementation of a novel approach. Trop Med Int Health. 2012;17(7):896-903. https://doi.org/10.1111/ j.1365-3156.2012.03004.

10. Fenwick A, Webster JP, Bosque-Oliva E, Blair L, Fleming F, Zhang Y, Garba A, Stothard J, Gabrielli AF, Clements A. The Schistosomiasis Control Initiative (SCI): rationale, development and implementation from 2002-2008. Parasitology. 2009;136(13):1719-30.

11. Kolaczinski JH, Kabatereine NB, Onapa AW, Ndyomugyenyi R, Kakembo AS, Brooker S. Neglected tropical diseases in Uganda: the prospect and challenge of integrated control. Trends Parasitol. 2007;23(10):485-93. https://doi.org/10.1016/j.pt.2007.08.007.

12. Webster JP, Molyneux DH, Hotez PJ, Fenwick A. The contribution of mass drug administration to global health: past, present and future. Phil Trans $R$ Soc B Biol Sci. 2014. Available at https://doi.org/10.1098/rstb.2013.0434. Accessed 8 Mar 2019.

13. WHO. Marketing authorization of pharmaceutical products with special reference to multisource (generic) products: a manual for National Medicines Regulatory Authorities (NMRAs). 2011. Available at http://www. who.int/medicines/areas/quality_safety/regulation_legislation/blue_book/ en/. Accessed 8 Mar 2019.

14. Tsepe WC. Studies on molluscicidal properties of some South African medicinal plants used in the control of schistosomiasis in KwaZulu-Natal. University of Durban-Westville; 2003. Available at https://researchspace.ukzn. ac.za/handle/10413/8605. Accessed 8 Mar 2019.

15. Odhiambo GO, Musuva RM, Odiere MR, Mwinzi PN: Experiences and perspectives of community health workers from implementing treatment for schistosomiasis using the community directed intervention strategy in an informal settlement in Kisumu City, western Kenya. BMC Public Health 2016, 16(1):986. Available at https://doi.org/10.1186/s12889-016-3662-0. Accessed 8 Mar 2019.

16. Bah S, Diallo D, Dembélé S, Paulsen BS. Ethnopharmacological survey of plants used for the treatment of schistosomiasis in Niono District, Mali. J Ethnopharmacol. 2006;105(3):387-99.

17. Allan LA, Kutima HL, Muya S, Ayonga D, Yole D: The efficacy of a herbal drug, Schitozim over praziquantel in the management of schistosoma mansoni infection in BALB/c mice. J Biol Agric Health Care 2014, 4:77-87. Available at https://www.researchgate.net/profile/Shadrack_Muya/ publication/259933852_The_Efficacy_of_a_Herbal_Drug_Schitozim_over_ Praziquantel_in_the_Management_of_Schistosoma_mansoni_Infection_in BALBC_mice/links/551135a00cf2a8dd79bff1db.pdf. Accessed 8 Mar 2019.

18. Yen J, Wilbraham L. Discourses of culture and illness in South African mental health care and indigenous healing, Part I: Western psychiatric power. Transcult Psychiatry. 2003:40(4):542-61.

19. Yen J, Wilbraham L. Discourses of culture and illness in South African mental health care and indigenous healing, Part II: African mentality. Transcult Psychiatry. 2003;40(4):562-84.

20. Hopa M, Simbayi L, Du Toit C. Perceptions on integration of traditional and western healing in the new South Africa. S Afr J Psychol. 1998;28(1):8-14.

21. Arksey H, O'Malley L. Scoping studies: towards a methodological framework. Int J Soc Res Methodol. 2005;8(1):19-32.

22. Levac D, Colquhoun H, O'Brien KK. Scoping studies: advancing the methodology. Implement Sci. 2010;5(1):69.

23. Anderson S, Allen P, Peckham S, Goodwin N. Asking the right questions: scoping studies in the commissioning of research on the organisation and delivery of health services. Health Res Policy Syst. 2008;6(1):7. https://doi.org/10.1186/1478-4505-6-7.

24. Davies KS. Formulating the evidence based practice question: a review of the frameworks. J Evid Based Libr. 2011;6(2):75-80.

25. Briggs J: The Joanna Briggs Institute: Levels of evidence and grades of recommendation working party. J Supporting 2014, 6. Available at https://www.researchgate.net/profile/Micah_Peters2/publication/319713049_2 017_Guidance_for_the_Conduct_of_JBI_Scoping_Reviews/links/59c355d4 of7e9b21a82c547f/2017-Guidance-for-the-Conduct-of-JBI-Scoping-Reviews.pdf. Accessed 14 July 2019.

26. Hutton B, Salanti G, Caldwell DM, Chaimani A, Schmid CH, Cameron C, loannidis JP, Straus S, Thorlund K, Jansen JP. The PRISMA extension statement for reporting of systematic reviews incorporating network meta-analyses of health care interventions: checklist and explanations. J Ann Intern Med. 2015;162(11):777-84.

27. Pluye P, Robert E, Cargo M, Bartlett G, O'cathain A, Griffiths F, Boardman F, Gagnon M-P, Rousseau M: Proposal: a mixed methods appraisal tool for systematic mixed studies reviews. J Montréal: McGill University 2011, 2:p. 1-8. Available at http://mixedmethodsappraisaltoolpublic.pbworks.com/w/file/ fetch/84371689/MMAT\%202011\%20criteria\%20and\%20tutoria|\%202011-06-2 9updated2014.08.21.pdf. Accessed 8 Mar 2019.

28. Ekor M: The growing use of herbal medicines: issues relating to adverse reactions and challenges in monitoring safety. Front Pharmacol 2014, 4:177. Available at https://doi.org/10.3389/fphar.2013.00177. Accessed 8 Mar 2019.

\section{Publisher's Note}

Springer Nature remains neutral with regard to jurisdictional claims in published maps and institutional affiliations.

\section{Ready to submit your research? Choose BMC and benefit from}

- fast, convenient online submission

- thorough peer review by experienced researchers in your field

- rapid publication on acceptance

- support for research data, including large and complex data types

- gold Open Access which fosters wider collaboration and increased citations

- maximum visibility for your research: over $100 \mathrm{M}$ website views per year

At BMC, research is always in progress.

Learn more biomedcentral.com/submission 